\title{
Contradiction, Surprise, and Cognitive Change: the Effects of Disconfirmation of Belief on Conservers and Nonconservers ${ }^{1}$
}

\author{
Scott A. Miller \\ University of Michigan
}

\begin{abstract}
This study examined children's reactions to violations of their expectancies concerning conservation of weight. Three groups were tested: nonconservers (mean $\mathrm{CA}=8$ years, 4 months), young conservers (mean $\mathrm{CA}=8$ years, 10 months), and older conservers (mean $\mathrm{CA}=11$ years). Surprise and cognitive change were the principal outcomes assessed. Contrary to expectation, observable surprise proved infrequent in all groups. In contrast, changes in conservation judgment were frequent, although the degree of change was reduced somewhat if an appropriate explanation was required. The three groups were generally indistinguishable in the extent to which they changed. Evidence of active resistance to change (as defined by explanations which denied the validity of the outcome) was absent in nonconservers but appeared in about half the conservers. Older conservers were no more likely to resist extinction than were younger conservers.
\end{abstract}

The knowledge which children acquire about the world obviously varies in its sources and its necessity. At the one extreme are empirically based, rote-learned facts; the various state capitals are a common example. At the other extreme, at least according to Piaget's theory, are the numerous concepts which have been the focus of Genevan research. In particular, Piaget (e.g., 1952) has claimed that concepts of conservation are dependent less on empirical regularities than on logical implications; for a

1 This paper is based on a thesis submitted to the Graduate School of the University of Minnesota in partial fulfilment of the requirements for the Ph.D. degree. The research was supported in part by a fellowship from the National Institute of Child Health and Human Development (Grant No. 1-T1-HD-105-05). The author is grateful to William R. Charlesworth, thesis advisor, and Patricia $H$. Miller for their many helpful suggestions, to Mervyn Bergman for technical assistance, and to Joanne Bergman for assistance in testing subjects. The cooperation of the principal and teachers at Northport Elementary School, Brooklyn Center, MN is also gratefully acknowledged. Author's address: Department of Psychology, University of Michigan, Ann Arbor, MI 48104.

Copyright (C) 1973 by Academic Press, Inc.

All rights of reproduction in any form reserved. 
child with concrete operational structures, conservation must be the case.

One purpose of the present study was to examine this claim of logical necessity. The strategy adopted was to produce an apparent violation of conservation. Two classes of reaction were measured. One was expressive response, with a particular emphasis on surprise. The expectation was that conservers would find nonconservation quite surprising. Tempering this expectation somewhat were the results of previous research: Of the four studies which had devised apparent violations of conservation (Achenbach, 1969; Charlesworth, 1964; Mermelstein \& Meyer, 1969; Mermelstein \& Shulman, 1967), only Mermelstein and Shulman had reported surprise in a substantial proportion of subjects. Methodological difficulties, however, made the results of these studies uncertain. Two problems in particular can be cited: failure to demonstrate that the children were conservers by standard measures; and the inevitable difficulty of inferring affective reaction from facial expression.

The second kind of outcome examined was cognitive change. Faced with apparent nonconservation, a conserver can either maintain his logical concept or revert to his earlier belief in nonconservation. The latter outcome has been termed extinction of conservation. As with surprise, a clear Piagetian prediction was possible: If concepts of conservation are logically necessary, extinction should not occur. Again, previous research was not in line with expectation. Seven studies had examined this prediction, five with respect to conservation of weight (Hall \& Kingsley, 1968; Hall \& Simpson, 1968; Kingsley \& Hall, 1967; Smedslund, 1961b; Smith, 1968), two for conservation of liquid quantity (Brison, 1966; Sullivan, 1967). All had employed essentially the same procedure: Apparent nonconservation is produced; the child is asked to explain the outcome; extinction or resistance is inferred from the explanation he provides. The studies by Hall and Simpson and Smith also elicited judgments on subsequent conservation trials. The results of these studies can be easily summarized: All reported a remarkably high incidence of apparent extinction.

The methodological difficulties of extinction research have been discussed at length elsewhere (Miller, 1971). Briefly, the major criticism that can be directed against previous studies is that their criteria for assessing extinction have been too limited; the possibility of a socially compliant "pseudoextinction" has correspondingly been too great. The present study attempted to minimize demand pressures in a situation utilizing a number of different measures.

A second interest of the study was in how nonconscrvers react when they see conservation. The same questions can be asked as for conservers: Is the child surprised by the violation of his expectancy? And 
does he change his belief? The first question has received little previous attention. Piaget's book on number (Piaget, 1952) does report that nonconservers sometimes find a return to the initial state of equality surprising; his observations of this phenomenon, however, are casual and unsystematic. The question is of interest for two reasons. The first is diagnostic: As with conservers, the presence or absence of surprise can be taken as an indication of the certainty with which the challenged belief is held. The second interest stems from the problem of cognitive motivation. There are numerous theories which posit that the motivation for cognitive change arises from some sort of discord between existing structures and new input (e.g., Charlesworth, 1969; Hunt, 1965; Smedslund, 1961c). Despite the popularity of such approaches, no study has demonstrated such reactions in a situation relevant to the development of Piagetian concepts. In particular, the various "cognitive conflict" training studies (e.g., Gruen, 1965; Smedslund, 1961c) have all inferred conflict rather than measured it directly.

Whereas surprise has not been measured in nonconservers exposed to conservation, cognitive change has frequently been examined (e.g., Overbeck \& Schwartz, 1970; Smedslund, 1961a; Smith, 1968). In the present study, the interest was less in the success of such training per se than in a number of related questions. Do the nonconservers show surprise? What is the relation between surprise and cognitive change? And is it any easier to promote training through direct feedback than it is to promote extinction, that is, is progressive change more likely than regressive?

A final focus of the study was on possible developmental changes in conservers' responses to nonconservation. Presumably, the strength and stability of concepts like conservation increase with the length of time that they have been in the cognitive system. If so, then both surprise and resistance to extinction should be greater in older than in younger conservers.

An overview of the study may help to tie these various threads together. The concept examined was conservation of weight. Three groups were tested: nonconservers, young conservers, and old conservers. Each group received feedback which consistently disconfirmed its expectancy concerning conservation. Two classes of reaction were measured: expressive response, with a particular emphasis on surprise; and cognitive change. Surprise was inferred from videotaped facial reactions, verbalizations, and delays in a reaction-time response contingent upon the outcome the latter measure adopted from Charlesworth, 1964; and Charlesworth \& Zahn, 1966). Cognitive change was inferred from the child's explanations for the outcomes, his judgments and explanations on a series of generalization trials, and his response to posttest questioning. 


\section{METHOD}

\section{Subjects}

The subjects were 130 second-, third-, and fifth-grade children from a middle-class suburb of Minneapolis. Of the 130 children, 69 were retained for the complete study: 23 second- and third-grade conservers ( 15 boys and eight girls, mean age $=8$ years, 10 months), 28 second- and thirdgrade nonconservers (eight boys and 20 girls, mean age $=8$ years, 4 months), and 18 fifth-grade conservers (12 boys and six girls, mean age $=11$ years $).$ Fifty-five children were rejected because of transitional performance on the pretest, and six fifth-graders were rejected because they were nonconservers.

\section{Apparatus}

All testing was conducted in a mobile laboratory trailer. The trailer was divided into two rooms separated by a one-way mirror. The subject was seated at a table facing the mirror; the experimenter sat to his right.

The central piece of apparatus was a hanging-pan balance scale. Outcomes on the scale could be read in two ways: by the alignment or nonalignment of the two pans, or by the movement of a pointer attached to the scale arm. The scale was capable of providing accurate feedback as to relative weight; it was also capable of providing systematically distorted feedback. Embedded in its base were two electromagnets, between which hung a soft iron bar attached to the underside of the scale arm. Activation of either magnet attracted the bar, causing the arm to swing to one or the other side and creating the appearance of unequal weights. The magnets were activated by silent foot pedals concealed beneath the table.

The remaining apparatus was designed to assess the subject's response to the feedback. Depression of either foot pedal not only activated the magnet but also started a reaction-time clock housed in the second room of the trailer. (On trials on which the trick was not desired, setting a toggle switch permitted starting the clock without activating the magnet.) The clock could be stopped by pressure on any of three 2 -in. diam buttons aligned horizontally along an $111 / 4$-in. $\times 4$-in. metal panel placed directly in front of the scale. Each of the buttons contained a colored drawing of the scale. The left button showed the scale with the left pan lowered; the middle button showed the scale balanced; and the right button showed the seale with the right pan lowered.

The second room also contained a videotape unit for recording facial expressions. The unit consisted of a videorecorder, monitor, and camera. Taping was accomplished through a small hole in the wall located slightly 
to the subject's left and at approximately the same height as his head. An observer housed in the second room operated the tape unit, registered reaction times and reset the clock, set the toggle switch as required, and recorded all relevant verbalizations.

\section{Procedure}

All subjects were tested individually by the same male experimenter. Although the procedure was continuous, three phases can be identified: pretraining and the conservation pretest; reaction-time and feedback trials; postfeedback trials and posttest questioning.

Pretest phase. The session began with some brief pretraining designed to assure that the subject possessed at least some understanding of the notion of weight and the operation of the scale. The pretraining combined verbal explanations of the scale's workings with demonstrations employing everyday objects. The examples included both equalities and inequalities.

The conservation pretest included four trials. The first three were conservation of equality: Two clay balls were weighed and found equal; one was then transformed and the conservation question asked. The three transformations, balanced for order within age, were into a pancake, a sausage, and three small balls. The form of the conservation question was as follows: "If we weighed them now, would the green weigh more, would they still weigh the same, or would the red weigh more?" followed by "Why do you think so?" The final trial was a conservation of inequality: A ball was shown (by means of the foot pedal) to weigh more

TABLE 1

Summary of Experimental Procedure

\begin{tabular}{cl}
\hline Trial & \multicolumn{1}{c}{ Description } \\
\hline $1-4$ & $\begin{array}{l}\text { Conservation pretest: three equality problems, one inequality problem } \\
-\end{array}$ \\
$\begin{array}{l}\text { Reaction-time practice and baseline: three trials of each } \\
5-7\end{array}$ & $\begin{array}{c}\text { Conservation feedback: two equality problems, one inequality problem } \\
\text { Conservation assessment: two equality problems on which } S \text { had received } \\
\text { feedback }\end{array}$ \\
10 & $\begin{array}{c}\text { Conservation assessment: equality problem on which } S \text { had not received } \\
\text { feedback }\end{array}$ \\
11 & $\begin{array}{l}\text { Conservation assessment: equality problem with cardboard squares } \\
\text { Conservation assessment: inequality problem in which } S \text { 's task was to make } \\
\text { the stimuli equal }\end{array}$ \\
Conservation assessment: equality problem without use of the scale \\
Posttest questioning
\end{tabular}


than a snake; the ball was then rolled into an identical snake and the conservation question asked.

Any subject whose performance did not place him in one of the desired groups, i.e., conserver or nonconserver at the younger age, or conserver at the older age, was discarded at this point. A child was considered a conserver if he answered all four questions correctly, a nonconserver if he answered all four incorrectly; any other pattern was regarded as transitional.

Reaction-time and feedback phase. The reaction-time panel was placed in front of the scale and introduced as a "way to tell me what things weigh without having to talk." The resemblance between the pictures on the buttons and the various positions of the scale was noted, and the subject was instructed to push the button that corresponded to the outcome on the scale. A series of practice trials followed, the experimenter moving the scale by hand and the subject lifting his hand from the start position (a square of tape on the table in front of him) to push the appropriate button. No subject experienced any appreciable difficulty.

Six "no-expectancy" reaction-time (RT) trials followed. The stimuli on these trials were encased in opaque bags. In all instances the two objects weighed the same; apparent differences were produced by means of the pedal. The first three trials served as further practice, the last three as baseline. Each of the three possible outcomes appeared once within a block of three trials, with their exact ordering balanced across subjects. The RT clock was started by the experimenter's stepping on the foot pedal at the movement of releasing the pans; it was stopped by the subject's button press.

The succeeding three RT trials consisted of conservation problems with feedback. Two of the trials were conservation-of-equality problems identical to those of the pretest (each of the three transformations appearing equally often across subjects); one was the conservation-ofinequality problem. The ordering of the particular trials was balanced within groups. The deviation from the pretest occurred following the subject's judgment and explanation. The subject was informed that the objects would be placed back on the scale and instructed to push the correct button "as soon as you see what they weigh."

The feedback on these trials consistently disconfirmed the subject's original belief about conservation. Thus, nonconservers received three trials with conservation outcomes; conservers received three with nonconservation outcomes. The latter result was accomplished through activation of the electromagnet. On the equality trials the ball was made to appear heavier than the transformed object; in one case the left side was heavier and in one case the right. On the inequality trial the magnet 
was used on the initial weighing to make the ball appear heavier; a subsequent honest weighing then revealed that the two snakes were equal.

The subject's first task on these trials was to press the correct button. Approximately $3 \mathrm{sec}$ after the button push the experimenter asked, "Why did that happen?" There followed a period of sympathetic, flexible questioning designed to elicit the child's true feelings about the outcome. Restatements of his prediction and the actual outcome were frequent, as were phrases such as "What do you really think?" and "Is there any other reason you can think of?" This questioning continued until the subject either appeared satisfied with an answer or was clearly unable to provide anything further.

The final measure obtained on these trials was of facial reactions. The videorecorder was turned on a few seconds before the stimuli were returned to the pans, and it continued recording until shortly after the experimenter asked "Why did that happen?"

Postfeedback phase. The postfeedback phase began with the removal of the reaction-time panel, coupled with an assurance that the objects would no longer be re-weighed. The trials that followed were an attempt to depart gradually from the pressures of the feedback situation. The first two were repetitions of the two conservation-of-equality transformations on which the subject had received feedback. The third employed the conservation-of-equality transformation from the pretest which had not been included in the feedback phase.

The last three trials were a greater departure. The first involved a change in both material and deformation: Two cardboard squares were weighed and found equal; one was then folded twice and the conservation question asked. The next trial returned to the domain of clay but changed the form of the question. After an initial weighing had established that a ball was heavier than a cross, the experimenter asked, "What could we do to these two things to make them weigh the same?" No manipulations were performed, but the subject was encouraged to give as many different answers as he could.

The final trial began with the removal of the seale. The subject was handed two clay balls and asked to judge whether they weighed the same; if necessary, they were adjusted until he agreed on the equality. One ball was then transformed (in the same manner as on the first conservation-of-equality trial) and the conservation question asked. Following his answer, the subject again held the objects and estimated their relative weights.

The session concluded with a period of posttest questioning which sought to elicit the child's true reactions to what had happened. Typically, this questioning included verbal formulations of the conservation 
problem, challenges to the child's answers (e.g., "But when we started you told me..."), requests to seek for explanations, and questions about how sure he was and whether he had changed his mind.

Children who had experienced apparent nonconservation were not debriefed immediately, since doing so would have increased the probability of unwanted communication. At the conclusion of the study itself, however, a classroom debriefing was provided for all subjects.

\section{Scoring}

Trials 12 and 13 were the only ones which departed from standard procedure and, thus, required a decision about criteria. A subject was credited with conservation on trial 12 if his response avoided a perceptually based solution of the form "Make the ball into a cross too." $\mathrm{He}$ was credited with a conservation judgment on trial 13 only if he gave an equality response both before and after holding the stimuli.

TABLE 2

Types of Nonconservation Explanations and Proportion of SubJects Giving at Least One Instance of the Different Types

\begin{tabular}{|c|c|c|}
\hline Type of explanation & $\begin{array}{c}\text { Young } \\
\text { conservers }\end{array}$ & $\begin{array}{c}\text { Old } \\
\text { conservers }\end{array}$ \\
\hline $\begin{array}{l}\text { Addition/subtraction: statement either that addition/sub- } \\
\text { traction has occurred or that addition/subtraction is the } \\
\text { only basis for a change in weight }\end{array}$ & .35 & 0 \\
\hline $\begin{array}{l}\text { Trick: statement that a trick has occurred, but with no at- } \\
\text { tempt to specify how it was accomplished }\end{array}$ & .04 & 0 \\
\hline $\begin{array}{l}\text { Scale malfumctioning: statement that the scale is either wrong } \\
\text { or rigged }\end{array}$ & 22 & .33 \\
\hline $\begin{array}{l}\text { Outcome specific to the scale: statement that the outcome re- } \\
\text { sults from the nature of scales, not from a true change in } \\
\text { weight }\end{array}$ & .04 & .22 \\
\hline $\begin{array}{l}\text { Pan-placement: statement that the outcome results from the } \\
\text { way the objects were placed on the pans }\end{array}$ & 22 & .33 \\
\hline $\begin{array}{l}\text { More clay to start with: statement that the heavier object } \\
\text { must have had more elay to start with }\end{array}$ & .17 & 0 \\
\hline $\begin{array}{l}\text { High-level: admission that nonconservation has occurred, but } \\
\text { with a more sophisticated explanation than that of the } \\
\text { typical nonconserver (e.g., "Some air escaped when you } \\
\text { rolled it out.") }\end{array}$ & .09 & .28 \\
\hline $\begin{array}{l}\text { Unequal weight distribution: statement that the total weight } \\
\text { of an object is a function of how the weight is distributed }\end{array}$ & .13 & .44 \\
\hline $\begin{array}{l}\text { Previous outcome: reference to a previous occurrence of non- } \\
\text { conservalion }\end{array}$ & .48 & .22 \\
\hline $\begin{array}{l}\text { Perceptual: reference to the perceptual appearance of the } \\
\text { objects }\end{array}$ & .91 & .83 \\
\hline
\end{tabular}


The explanations which accompanied conservation judgments were categorized for both type (e.g., inversion, compensation) and adequacy. The percentages of interrater agreement ranged from 94 to $100 \%$. The explanations advanced for nonconservation were also categorized into types; these types are presented in Table 2 . Reliabilities were calculated for the responses of the conservers in the feedback and postfeedback phases. Interrater agreement was $94 \%$ for the answers of young conservers and $89 \%$ for those of old conservers.

Each child's videotape was independently rated by two judges. Six categories of expressive response were utilized: neutral, serious, thoughtful, curious, amused, and surprised. The rating period was divided into three phases; only data from the second phase, however, will be reported here. This phase began with the onset of feedback and continued until the subject made his $\mathrm{RT}$ response.

Interrater agreement proved to be only moderate. The percentage of agreement across all three rating periods was $81 \%$. That for the second period alone was $76 \%$.

\section{RESULTS}

\section{Pretest Data}

The pretest yielded a significant sex difference: among the younger subjects, boys were more likely to be conservers than were girls $\left[\chi^{2}(1)=\right.$ $5.45, p<.05]$. The obvious possibility raised by this finding is that comparisons between conservers and nonconservers might be confounded by sex differences. It should be noted, therefore, that there is no indication that such confounding occurred.

The difficulty of the pretest is also worth noting. Although unexpected, this difficulty does serve to forestall a possible criticism: With such a rigorous test, it seems certain that children identified as conservers really were genuine conservers. This conclusion is supported by the fact that $93 \%$ of the conservation judgments were accompanied by adequate explanations.

The pretest items were not of equal difficulty. The proportion of conservation responses by transitional subjects was $72 \%$ on the equality trials but only $7 \%$ on the inequality (snake) trial.

Finally, the 6-month difference in average age between noneonscrvers and young conservers should be noted.

\section{Measures of Surprise}

Facial reactions. Table 3 indicates the proportion of subjects emitting the various types of expressive response. No distinction is drawn between 
TABLE 3

Proportion of Subjects Emitting the Different Types of Expressive Response During the Second Phase of the Feedback Trials

Neutral Serious Thoughtful Curious Amused Surprised

Trial 5

\begin{tabular}{|c|c|c|c|c|c|c|}
\hline Nonconservers & .36 & 0 & .14 & .32 & .39 & .11 \\
\hline Young conservers & .30 & .04 & .13 & .26 & .52 & .09 \\
\hline Old conservers & .28 & .06 & .11 & .39 & .50 & .06 \\
\hline \multicolumn{7}{|l|}{ Trial 6} \\
\hline Nonconservers & .46 & 0 & .04 & .36 & .29 & .04 \\
\hline Young conservers & .35 & .04 & .30 & .30 & .39 & .09 \\
\hline Old conservers & .50 & .06 & 0 & .11 & .39 & 0 \\
\hline \multicolumn{7}{|l|}{ Trial 7} \\
\hline Nonconservers & .61 & .04 & .18 & .29 & .14 & 0 \\
\hline Young conservers & .39 & 0 & .17 & .09 & 48 & .04 \\
\hline Old conservers & .61 & .06 & .11 & .17 & .17 & .06 \\
\hline
\end{tabular}

cases in which the response was the only one rated and cases in which it was one of several. The only exception is for the neutral category: a subject was designated as neutral only if he gave no other response.

The category of greatest interest is that of surprise. Table 3 reveals that surprise reactions were quite infrequent. With 69 subjects and three trials apiece, there were 207 occasions on which surprise might have appeared. These 207 opportunities yielded 11 instances of observable surprise. The three groups did not differ in tendency to show surprise; young conservers contributed five of the instances, nonconservers four, and older conservers two.

Surprise was the only expressive response for which specific expectations were stated. The data in Table 3 , however, permit two general conclusions with respect to the other types of expressive reaction. One is that the overall level of responding was low. The second is that the pattern of responding was remarkably similar in the three groups.

Verbalizations. The interest here was in spontaneous verbalizations emitted between the stimulus onset and the experimenter's question about the outcome. Nineteen subjects produced such verbalizations on at least one trial; five verbalized twice. The three groups did not differ in proportion of subjects verbalizing. If type of verbalization is taken into account, however, a significant difference does emerge. The majority of verbalizations were either simple statements of the outcome or questions about whether to push the button. Six subjects, however, produced utterances which could be interpreted as indicating surprise, e.g., "That's funny," or "Hey! They're the same!" Five of these subjects were young conservers; one was an older conserver. The difference between young 
conservers and nonconservers was significant $(p=.014$, Fisher's Exact Test). This finding must be qualified, however, by the statement that verbalization was rare whatever the subject's belief.

Reaction time. Analyses here were based on the difference between the subject's reaction time on a feedback trial and his baseline for the outcome on that trial. The mean difference scores on the first feedback were $2.61 \mathrm{sec}$ for nonconservers, 2.78 for young conservers, and 2.33 for old conscrvers. The comparable figurcs for all three trials combined were 2.46, 2.45, and 1.80. None of the differences between groups approached significance.

These difference scores reflect an approximate doubling of the baseline values. Thus, the children were slowed down on the feedback trials. Clearly, however, an inference that surprise was responsible for the increase must remain tentative in the absence of facial indications of surprise.

\section{Measures of Cognitive Change}

There were eight trials following the first occurrence of feedback. The percentage of changed predictions on these trials was $49 \%$ for nonconservers, $69 \%$ for young conservers, and $64 \%$ for old conservers. Figure 1 plots the course of change across lrials.

The first finding to note is that all three groups showed substantial change. They were not equivalent in the extent to which they changed.

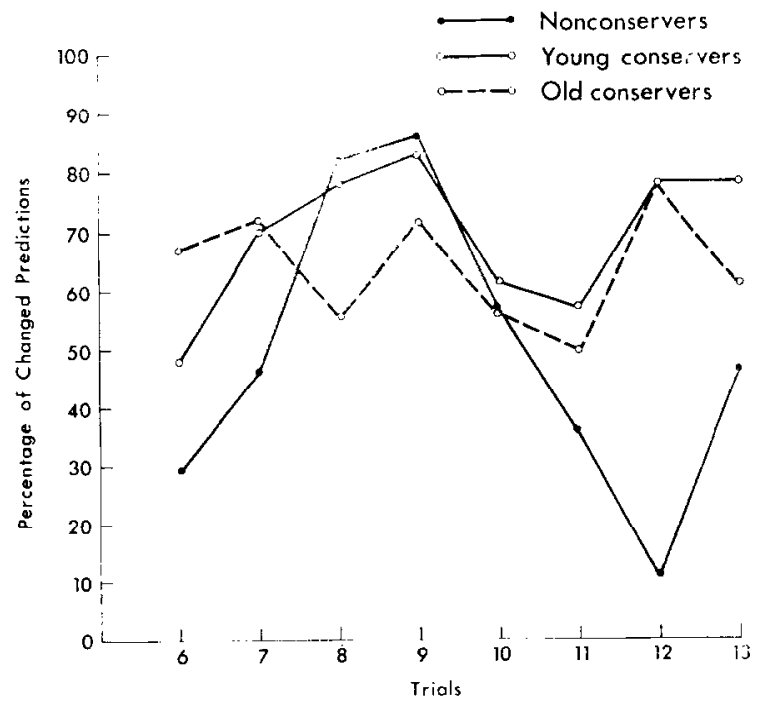

FIa. 1. Change in prediction by the three groups across trials. 
Young conservers and old conservers did not differ significantly $[t(39)=$ $.53]$. Nonconservers, however, changed significantly less often than young conservers $[t(49)=2.65, p<.05]$.

The source of the significant difference can be seen in Fig. 1. Change scores increased for both groups through trials 8 and 9 (transformations on which the subject had received feedback), then decreased on 10 and 11 (generalization trials). On trial 12 , however, all subjects tended to give nonconservation answers. This performance may be another reflection of the difficulty of certain forms of the inequality problem (recall the pretest data). In any case, since it was not included in the pretest, trial 12 is questionable as a measure of change. If it is omitted, the proportions of change are $68 \%$ for young conservers and $55 \%$ for nonconservers, a nonsignificant difference $[t(49)=1.73, p>.10]$.

The analysis of conservation judgments must be supplemented by a consideration of the explanations advanced for the judgments. These explanations were dichotomized into adequate vs inadequate for conservation answers and perceptual vs nonperceptual for nonconservation answers. A trial was scored as "adequate" if at least one adequate explanation was present but as "perceptual" only if no other explanation appeared. Trial 12 was necessarily omitted, since it did not require an explanation.

Nonconservers who changed to conservation were able to provide a logical justification for $89 \%$ of their answers. Overall, nonconservers gave conservation judgments plus logical explanations on $48 \%$ of the trials following the first feedback. Young conservers who switched to nonconservation offered perceptual explanations for $66 \%$ of their answers; over all trials, their percentage of nonconservation choices accompanied by perceptual explanations was $45 \%$. Thus, again the two groups proved equivalent.

The analyses thus far have focused on appropriate explanations. It is also possible to analyze the explanations which were not appropriate for the extent to which they suggest active resistance to change. For this analysis, responses to the posttest questioning were grouped with those to the feedback and postfeedback trials.

Ninety-four percent of the inadequate explanations by nonconservers consisted either of perceptual answers or of inability to respond. As Table 2 indicates, the responses of conservers were considerably more varied. The highest level of resistance is defined by the first six categories, these being highest because each denies that the unexpected outcome has really occurred. Thirteen young conservers produced at least one such explanation; one nonconserver did $\left[\chi^{2}(1)=15.22\right.$, $p<.001]$. Perhaps more surprising is the fact that even simpler forms 
of resistance did not appear in nonconservers. Thus, 11 young conservers offered at least one Previous Outcome response, as compared to one nonconserver $\left[\chi^{2}(1)=11.39, p<.001\right]$. In short, indications of resistance were much more frequent in conservers than in nonconservers.

The same comparisons can be drawn between young conservers and old conservers. These groups did not differ in number of changed predictions, or in number of changed predictions accompanied by a perceptual explanation, or in the extent to which their explanations suggested at least some form of resistance. Thus, $83 \%$ of the younger and $89 \%$ of the older conservers were able to provide at least one nonperceptual explanation. Among these, 57\% of the younger and $50 \%$ of the older subjects offered at least one explanation which denied the validity of nonconservation.

This latter finding is surprising, since it means that the clearest indications of resistance were no more frequent in older than in younger conservers. The two groups did differ somewhat, however, in type of resistance. Eight young conservers suggested that addition or subtraction might account for the inequality; no older subject suggested such deception ( $p=.005$, Fisher's Exact Test). The older children were more likely to attribute nonconservation to some sort of malfunctioning of the scale. They also were significantly more likely to utilize the categories of High Level and Unequal Weight Distribution $\left[\chi^{2}(1)=6.65\right.$, $p<.01]$. These latter types of explanation seem to reflect a "sophisticated" form of nonconservation: The child admits that nonconservation has occurred, but attempts to encompass the discrepant phenomenon within an operational framework.

\section{Interrelations between Surprise and Cognitive Change}

The infrequency of observable surprise limits what can be said in this section. It is possible, nevertheless, to attempt a partial examination of the original question. Eight children showed either facial or verbal indications of surprise on the first feedback trial. How do these children compare with the rest of the sample on measures of cognitive change? With such a small $N$ it is impossible to draw any rigorous conclusions. Nevertheless, it can be noted that such a comparison yields no evidence that surprised subjects were any different from nonsurprised ones in their tendency to change their beliefs.

\section{DISCUSSION}

Several unexpected findings emerged from this study. One was the extremely low level of observable surprise. This result was not entirely unexpected in nonconservers; neither previous research nor theoretical 
analysis provided a clear basis for predicting whether surprise would appear in such subjects. The present results suggest that nonconservation (at least of weight) is simply not the sort of concept whose violation is surprising. The fact that it is not raises some doubt about motivational models which place the impetus for cognitive progress in feelings of surprise or conflict. While the present manipulation is hardly a definitive test of such models, the fact remains that no training study has as yet demonstrated surprise or conflict in preoperational children.

The absence of surprise in conservers was much more unexpected. If valid, this result would appear to contradict Piaget's claim that conservation is experienced as logically necessary. Beforc such a conclusion is accepted, however, several possible objections must be considered. The most basic objection is that the absence may be only apparent and not real-a reflection of the difficulties inherent in measuring expressive response. This possibility can certainly not be discounted. Nevertheless, the infrequency of observable surprise strongly suggests that most conservers did not find the violation of conservation surprising.

The next question is whether the absence of surprise really contradicts Piaget's claims concerning logical necessity. A full discussion of this issue, however, requires consideration of the extinction data as well.

This study produced more evidence of resistance to extinction than had the majority of previous studies. Thus, in three studies Hall and his associates (Hall \& Kingsley, 1968; Hall \& Simpson, 1968; Kingsley $\&$ Hall, 1967) found that only 10 of 92 conservers were able to resist extinction by uttering an explanation which denied the validity of the nonconservation outcome. In this study 22 of 41 conservers produced such explanations. Similarly, both Hall and Simpson (1968) and Smith (1968) reported that conservers would readily switch to nonconservation predictions following an extinction experience. The present study, however, found that only $66 \%$ of such changed predictions were accompanied by typical nonconservation explanations. In both cases, apparent extinction proves at least somewhat deceptive upon closer examination.

Once this first conclusion is granted, however, a second conclusion must be that a substantial degree of apparent extinction still emerges. The strong indication, from both this and previous studies, is that many conservers really do abandon conservation when confronted with counterinstances. How can such a finding be encompassed within a Piagetian framework? Two suggestions will be offered. Both are relevant not only to extinction but also to explaining the low level of surprise.

The first suggestion is that the period during which a concept develops its full generality and stability may be more extended than has 
previously been thought. Perhaps children who have mastered conservation by the traditional measures still require a "stabilization phase" during which the concept acquires the certainty which it carries for adults. Certainty would then be an endpoint, perhaps reached more quickly by some than by others, but eventually reached by all. Testing this notion would obviously require older subjects than the old conservers of this study.

The second suggestion is that the various Piagetian concepts may vary in the extent to which they entail feelings of necessity. Conservation of weight, in particular, appears to have more of a "physical fact" basis than do many Piagetian concepts; perhaps it never becomes a necessity for some people. Such a finding need not imply that other Piagetian concepts are equally extinguishable.

The one subset of the data which remains to be discussed concerns cognitive change by nonconservers. The degree of apparent training was substantial. While some change appeared to reflect a rote-learned pseudoconservation, some appeared genuine: Correct judgments and appropriate explanations appeared throughout the posttest trials. How can the success of such empirically oriented training be explained? Three answers can be briefly suggested. They are that feedback training might produce genuine progress if: there are developmentally earlier conservations on which the trained conservation can build; the child is already fairly close to developing the concept naturally; and the trained concept has a basis in physical knowledge. All of these conditions were present here.

Several directions can be suggested for future study. Methodologically, the major task is to obtain better measures of the outcomes under investigation here. Perhaps the most promising new measures would be physiological reactions in the case of affective response and a delayed posttest in the case of cognitive change. Substantively, the most interesting question concerns the problem of logical necessity. The suggestions for further research have already been implied: Devise violations for a variety of Piagetian concepts, and measure the effects at a number of different points in development. Such research should provide a firmer basis for evaluating this central Piagetian claim.

\section{REFERENCES}

Achenbach, T. M. Conservation of illusion-distored identity: Its relation to MA and $\mathrm{CA}$ in normals and retardates. Child Development, 1969, 40, 663-679.

Brison. D. W. Acceleration of conservation of substance. Journal of Genetic Psychology, 1966, 109, 311-322.

Charlesworth, W. R. Instigation and maintenance of curiosity behavior as a 
function of surprise versus novel and familiar stimuli. Child Development, 1964, $35,1169-1186$.

Charlesworth, W. R. The role of surprise in cognitive development. In D. Elkind and J. H. Flavell (Eds.), Studies in cognitive development. New York: Oxford University Press, 1969.

Charlesworth, W. R., \& Zahn, C. Reaction time as a measure of comprehension of the effects produced by rotation on objects. Child Development, 1966, 37, $253-268$.

Gruen, G. E. Experiences affecting the development of number conservation in children. Child Development, 1965, 36, 963-979.

Hall, V. C., \& Kingsuey, R. Conservation and equilibration theory. Journal of Genetic Psychology, 1968, 113, 195-213.

Hall, V. C., \& Simpson, G. J. Factors influencing extinction of weight conservation. Merrill-Palmer Quarterly, 1968, 14, 197-210.

Huxt, J. MCV. Intrinsic motivation and its role in psychological development. Nebraska Symposium on Motivation. 1965, 13, 189-282.

Krngsley, R. C., \& Hall, V. C. Training conservation through the use of learning sets. Child Development, 1967, 38, 1111-1126.

Mermelsteis, E., \& Meyer, E. Conservation training techniques and their effects on different populations. Child Development, 1969, 40, 471-490.

Mermelstein, E., \& Shulman. L. S. Lack of formal schooling and the acquisition of conservation. Child Development, 1967, 38, 39-52.

Miller, S. A. Extinction of conservation: A methodological and theoretical analysis. Merrill-Palmer Quarterly, 1971, 17, 319-334.

Overbeck, C., \& Schwartz, M. Training in conservation of weight. Journal of Experimental Child Psychology, 1970, 9, 253-264.

Piaget, J. The child's conception of number. New York: Humanities Press, 1952.

SMEdSLUNd, J. The acquisition of conservation of substance and weight in children: II. Fxternal reinforcement of enservation of weight and of the operations of addition and subtraction. Scandinavian Journal of Psychology, 1961, 2, 71-84. (a)

SMEDsLLND, J. The acquisition of conservation of substance and weight in children: III. Extinction of conservation of weight acquired "normally" and by means of mmpirical controls on a balance. Scandinavian Journal of Psychology, 1961, 2, 85-87. (b)

Smedslund, J. The acquisition of conservation of substance and weight in children: V. Practice in conflict situations without external reinforcement. Scandinavian Journal of Psychology, 1961, 2, 153 155. (c)

Sмiтн, I. D. The effects of training procedures upon the acquisition of conservation of weight. Child Development, 1968, 39, 515-526.

Sullivan, E. V. Acquisition of conservation of substance through film modeling techniques. In D. W. Brison and E. V. Sullivan (Eds.), Recert research on the acquisition of conservation of substance. Ontario Institute for Studies in Education. 1967, 11-23. 